\title{
Examining the Efficacy of Peer Feedback as Part of the Writing Process in an Introductory Biology Course
}

\section{Laurie Pacarynuk and Jennifer Burke}

\author{
University of Lethbridge, Department of Biological Sciences, 4401 University Dr W, Lethbridge \\ AB T1K 3M4 CAN \\ (pacarynuk@uleth.ca; jennifer.burke2@uleth.ca)
}

\begin{abstract}
A goal of introductory biology labs is to introduce students to scientific writing by having them write lab reports. With several lab sections taught by different instructors, consistency in grading is a problem. Another challenge is that students do not appear to engage with instructor feedback; they see writing as subjective, or fail to use the feedback to improve. One approach to these problems is having students carry out peer assessment with the goals of: encouraging engagement in the process of writing, introducing students to the peer review process (fundamental to science), and addressing inconsistencies in grading. Students in Biology 1010 used Moodle Workshop to grade exemplar Introductions and Discussions. They then prepared and peer evaluated Introductions and Discussions. Students were surveyed (22\% responding: 44/200). Forty-five percent of respondents disagreed with the statement: I feel that the peer-feedback that I received helped to improve my writing; however, $90 \%$ of these identified stress and/or the belief that they would have received higher marks from their instructors as the reason(s) behind their negative evaluations. Eighty-six percent agreed with the statement: I feel that engaging in the peer-feedback process helped to strengthen my critical reading skills. Overall, preliminary results support the use of peer feedback.
\end{abstract}

Keywords: scientific writing, peer assessment

\section{Mission, Review Process \& Disclaimer}

The Association for Biology Laboratory Education (ABLE) was founded in 1979 to promote information exchange among university and college educators actively concerned with teaching biology in a laboratory setting. The focus of ABLE is to improve the undergraduate biology laboratory experience by promoting the development and dissemination of interesting, innovative, and reliable laboratory exercises. For more information about ABLE, please visit http://www.ableweb.org/.

Advances in Biology Laboratory Education is the peer-reviewed publication of the conference of the Association for Biology Laboratory Education. Published articles and extended abstracts are evaluated and selected by a committee prior to presentation at the conference, peer-reviewed by participants at the conference, and edited by members of the ABLE Editorial Board. Published abstracts are evaluated and selected by a committee prior to presentation at the conference.

\section{Citing This Article}

Pacarynuk L, Burke J. 2020. Examining the efficacy of peer feedback as part of the writing process in an introductory biology course. Article $78 \mathrm{In}$ : McMahon K, editor. Advances in biology laboratory education. Volume 41. Publication of the 41st Conference of the Association for Biology Laboratory Education (ABLE). https://doi.org/10.37590/able.v41.abs78

Compilation (C) 2020 by the Association for Biology Laboratory Education, ISBN 1-890444-17-0. All rights reserved. No part of this publication may be reproduced, stored in a retrieval system, or transmitted, in any form or by any means, electronic, mechanical, photocopying, recording, or otherwise, without the prior written permission of the copyright owner.

ABLE strongly encourages individuals to use the exercises in this volume in their teaching program. If this exercise is used solely at one's own institution with no intent for profit, it is excluded from the preceding copyright restriction, unless otherwise noted on the copyright notice of the individual chapter in this volume. Proper credit to this publication must be included in your laboratory outline for each use; a sample citation is given above. 